https://doi.org/10.1590/198053145997

\title{
FORMAÇÃO DE PROFESSORES DE EDUCAÇÃO INFANTIL E O PIBID
}

Daniela Oliveira Guimarães'

\section{Resumo}

Este artigo tem como objetivo compreender peculiaridades da formação de professores da educação infantil e discutir especificidades da docência nesse contexto. Para tal, apresenta reflexões acerca do trabalho formativo do Programa Institucional de Bolsas de Iniciação à Docência (Pibid) Pedagogia/Educação Infantil numa universidade federal nos anos de 2016 e 2017, a partir da análise dos registros produzidos no processo. Os interlocutores privilegiados são: Mikhail Bakhtin, na consideração do caráter alteritário da formação; e, paralelamente, Maurice Tardif, Antonio Nóvoa e Maria do Céu Roldão, que sublinham a centralidade da prática na formação e a profissionalidade dos professores. Nesse cenário, são tematizados desafios da docência na $1^{a}$ etapa da educação básica; de modo especial, a construção de práticas pedagógicas centradas nas crianças.

EDUCAÇÃO INFANTIL • ALTERIDADE • FORMAÇÃO DE PROFESSORES • PIBID

\section{TEACHER EDUCATION FOR EARLY CHILDHOOD EDUCATION AND PIBID}

\section{Abstract}

This article aims to understand specificities of early childhood teacher education and the specificities of early childhood teaching. To this end, it reflects on the formative work of PIBID [Programa Institucional de Bolsas de Iniciação à Docência] Pedagogy/Early Childhood Education in a federal university in 2016 and 2017 by analyzing the records produced in the process and by dialoguing with the ideas of Mikhail Bakhtin for considering the alterity of education, as well as those of Maurice Tardif, Antonio Nóvoa and Maria do Céu Roldão, who emphasize the centrality of practice in teacher education and professionality. In this framework, the article discusses the challenges of teaching in early childhood education and particularly the construction of child-centered pedagogical practices.

EARLY CHILDHOOD EDUCATION • ALTERITY • TEACHER EDUCATION • PIBID 


\section{FORMATION DES ENSEIGNANTS DE LA PETITE ENFANCE ET LE PIBID}

\section{Résumé}

Cet article vise à comprendre les particularités de la formation des enseignants de la petite enfance et à discuter les spécificités d'un tel enseignement. À cette fin, il présente des réflexions sur le travail de formation du PIBID (Programa Institucional de Bolsas de Iniciação à Docência [Programme Institutionnel de Bourses d'Initiation a l'Enseignement]) Pédagogie/ Éducation de la Petite Enfance dans une université fédérale en 2016 et 2017, à partir de l'analyse des notes prises au cours du processus. Les interlocuteurs suivants ont été privilégiés: Mikhail Bakhtin, pour les considérations sur le caractère altéritaire de la formation; Maurice Tardif, Antonio Nóvoa et Maria do Céu Roldão, parce qu'ils mettent en relief la centralité de la pratique dans la formation et la professionnalité des enseignants. Ce contexte rend possible la thématisation des défis qui se posent à l'enseignement de cette première étape de l'éducation de base, en particulier la construction de pratiques pédagogiques centrées sur les enfants.

ÉDUCATION DE LA PETITE ENFANCE • ALTÉRITÉ • FORMATION DES ENSEIGNANTS • PIBID

\section{FORMACIÓN DE PROFESORES DE EDUCACIÓN INFANTIL $Y$ EL PIBID}

\section{Resumen}

Este artículo tiene el objetivo de comprender peculiaridades de la formación de profesores de Educación Infantil y discutir especificidades de la docencia en este contexto. Para ello, presenta reflexiones acerca del trabajo formativo del PIBID (Programa Institucional de Bolsas de Iniciação à Docência) Pedagogía/Educación infantil en una universidad federal en los años 2016 y 2017, a partir del análisis de los registros producidos en el proceso. Los interlocutores privilegiados son Mikhail Bakhtin, en la consideración del carácter de alteridad de la formación y, paralelamente, Maurice Tardif, Antonio Nóvoa y Maria do Céu Roldão, que subrayan la centralidad de la práctica en la formación y profesionalidad de los profesores. En este escenario, se tematizan desafíos de la docencia en la $1^{a}$ etapa de la Educación Básica; de modo especial, la construcción de prácticas pedagógicas centradas en los niños. 
O saber dos professores é profundamente social [...] relação entre mim e os outros repercutindo em mim, relação com os outros em relação a mim, e, também, relação de mim para comigo mesmo quando essa relação é presença do outro em mim mesmo. (TARDIF, 2014)

STE TRABALHO TEM COMO PROPÓSITO DISCUTIR A FORMAÇÃO DE PROFESSORES DA educação infantil e as especificidades da docência nesse contexto, a partir das experiências do Programa Institucional de Bolsas de Iniciação à Docência (Pibid) em Pedagogia-Educação Infantil, numa universidade pública federal ao longo dos anos 2016 e 2017. Na discussão, destaca-se a qualidade alteritária e formativa do projeto, tanto para os licenciandos do curso de Pedagogia como para os professores supervisores das escolas parceiras no Programa.

O Pibid foi criado em 2007, no âmbito da Coordenação de Aperfeiçoamento de Pessoal de Nível Superior (Capes), ligado ao Ministério da Educação (MEC). Trata-se de um Programa que oferece bolsas para estudantes de cursos de licenciatura, professores supervisores de escola de educação básica e coordenadores, professores universitários, tendo em vista fomentar a formação inicial para a docência a partir da interação com a prática pedagógica. Os licenciandos planejam e coordenam ações pedagógicas no contexto escolar, experimentando-se ativamente na profissão e discutindo com professores supervisores e coordenadores os sentidos das experiências vividas (ANDRÉ, 2016).

O Pibid destaca-se como política pública federal de formação de professores com impacto importante na valorização da prática como terreno formativo. Por outro lado, é um programa episódico, de acesso restrito nas universidades, não universal, o que enseja a discussão sobre a inserção mais ativa dos licenciandos 
nas escolas ao longo dos cursos de Pedagogia e outras licenciaturas. Coloca-se como questão: como irradiar algumas peculiaridades do Pibid nas disciplinas curriculares, de forma especial nos estágios? De fato, no contraponto das relações hierarquizadas, o Programa potencializa o diálogo da escola de educação básica com a universidades, provocando as duas instâncias para a construção de um espaço híbrido de formação, possibilitando a todos os envolvidos novas aprendizagens, o que poderia estar presente de forma efetiva nos cursos de licenciatura (ANDRÉ, 2016).

$\mathrm{Na}$ universidade aqui referida, o Pibid no curso de Licenciatura em Pedagogia inicia-se em 2011, envolvendo os anos iniciais do ensino fundamental. Em 2014, a educação infantil passa a integrar também o Programa, com 13 alunos licenciandos, três professores supervisores e uma coordenadora.

Ao longo de quatro anos de vigência do Programa na Pedagogia/Educação Infantil (de 2014 até 2017), participaram cerca de 30 alunas licenciandas em Pedagogia e sete professoras supervisoras em duas escolas federais, a Escola de Educação Infantil da Universidade Federal do Rio de Janeiro (EEI/UFRJ) e o Centro de Referência em Educação Infantil Realengo (Creir), do Colégio Pedro II.

O presente trabalho focaliza os últimos anos do Projeto, 2016 e 2017, quando participaram do trabalho 13 licenciandas e três professoras em três turmas de crianças de três a seis anos. ${ }^{1}$ As licenciandas eram todas mulheres, entre 20 e 25 anos, estudantes de Pedagogia. As professoras, também mulheres, entre 35 e 45 anos, eram pedagogas e especialistas em educação infantil.

No ano de 2016, foram produzidas 26 atas dos encontros semanais coletivos que compunham o trabalho formativo. Em 2017, foram produzidas 24 atas. Além disso, ao longo dos dois anos, foram compilados registros reflexivos individuais mensais de licenciandas e professoras. Neste trabalho, esse material é compreendido como documentação do processo formativo, mobilizador de novos olhares e perspectivas sobre cada situação vivida, e parte dele será analisada, tendo em vista a discussão das especificidades da docência e da formação dos professores da educação infantil.

Nesta reflexão, consideramos que a formação acontece a partir da experiência alteritária; ou seja, nas relações entre estudantes de Pedagogia e professores experientes que desafiam, tensionam perspectivas sobre as práticas e produzem deslocamentos em cada participante do Projeto. A perspectiva da alteridade alinha-se com as proposições da Filosofia da Linguagem, especialmente o trabalho de Mikhail Bakhtin (2003). Para o autor, constituímo-nos na relação com o outro. A palavra do outro e seu tom afetivo-volitivo vão ao encontro de nossa autossensação interior, nomeando-a, dando-lhe acabamentos, formando-a:

[...] o homem tem uma necessidade estética absoluta do outro, do seu ativismo que vê, lembra-se, reúne, e unifica,

1 Referimo-nos às licenciandas e supervisoras no feminino, pois, ao longo dos anos de trabalho aqui focalizados, havia somente mulheres participantes no Projeto. 
que é o único capaz de criar para ele uma personalidade externamente acabada; tal personalidade não existe se o outro não a cria. (BAKHTIN, 2003, p. 33)

Essas ideias coadunam-se com as discussões sobre a dimensão social do saber docente e da formação de professores. A dimensão alteritária e relacional da formação e da profissão docente ganha relevo na valorização do professor como profissional reflexivo (SCHON, 1983). Também se relaciona com a visão da formação de professores a partir de dentro (da prática e da profissão), valorizando o conhecimento docente numa vertente pública, tendo em vista a construção de conhecimento sobre a prática pela análise e problematização desta entre pares (NÓVOA, 2013).

De modo especial, a partir do diálogo com Nóvoa (2013), é importante considerar a presença da profissão na formação, pela valorização do conhecimento docente e pelo reforço da educação numa dimensão pública e coletiva. Trata-se de dar relevo à teorização da prática e aos espaços de reflexão sobre as experiências cotidianas que as desviam do automatismo, da alienação, do praticismo. A prática é assumida como lugar privilegiado de formação num trabalho crítico e colegiado que envolve a construção da intencionalidade pedagógica num movimento de interlocução entre professores experientes e entre eles e outros em formação.

Para Nóvoa (2013), esse movimento ganha força a partir da criação de uma nova realidade organizacional. De modo especial, na construção de um professor coletivo e na constituição de modos de produção e regulação do trabalho por equipes de professores, no contraponto das tradições individualistas e da tendência às ações com forte regulação externa. Nessa perspectiva, uma nova realidade organizacional implica a criação de um espaço de integração entre os formadores da universidade, os professores da educação básica e os licenciandos em formação inicial. Entendemos que o Pibid representa um caminho nessa direção pela integração de professores universitários, professores da educação básica e licenciandos em espaços e tempos comuns de reflexão e organização da prática pedagógica.

Em consonância, Tardif (2014) afirma que, no contexto da pluralidade dos saberes docentes, ganham destaque os saberes experienciais que têm origem na prática cotidiana e tornam-se conscientes para o professor a partir de um movimento de organização deles no discurso, na relação com o coletivo. Para o autor, “é através do confronto entre os saberes produzidos pela experiência coletiva dos professores que os saberes experienciais adquirem certa objetividade” (2014, p. 52). Nessas situações, os professores olham suas práticas de outras maneiras, a partir do olhar dos outros (colegas, licenciandos, etc.) e "retraduzem" sua formação inicial. Ou seja, "a experiência provoca um efeito de retomada crítica dos saberes adquiridos antes e fora da prática profissional” (TARDIF, 2014, p. 53). Ao mesmo tempo, os estudantes em formação, quando em diálogo com professores regentes, vivem a oportunidade de contato com o saber em construção, participando com suas interrogações, seus encantamentos, suas interpretações. 
Esse foi um movimento experimentado de forma intensa no Pibid/ Educação Infantil aqui focalizado. O cotidiano do trabalho formativo foi marcado pela construção de espaços e tempos de diálogo, confronto de pontos de vista, concretizados nos planejamentos coletivos, exposições de práticas, análises conjuntas dessas exposições, textos reflexivos sobre as experiências observadas e vividas nas escolas. Assim, ver-se pelo olhar do outro e produzir novas visões sobre práticas compartilhadas constituíam a formação tanto das licenciandas como das professoras supervisoras no processo experimentado em grupo.

O movimento formativo acontecia tendo em vista fortalecer a docência como profissão, o que, de acordo com Gatti (2016), envolve a capacidade de usar conhecimentos teóricos e práticos apropriados em situações relevantes, recriando-os no processo reflexivo constante.

Essa perspectiva tem especial relevo no campo da educação das crianças de 0 a 6 e na formação de seus professores. A educação das crianças pequenas nasce no Brasil no final do século XIX e início do século XX, aliada à filantropia, à subordinação, às ideias de guarda, proteção e tutela, sob influência jurídico-policial, médico-higienista e religiosa (KUHLMANN, 1998). Hoje, a construção do perfil do/a professor/a de educação infantil no plano profissional é um importante desafio político e formativo em nosso país, tendo em vista desviar-se dos sentidos da maternagem, do trabalho doméstico, e ao mesmo tempo, das peculiaridades do ensino fundamental (MICARELLO, 2013).

Desde a Constituição de 1988, a educação é compreendida como direito das crianças e, na promulgação da Lei de Diretrizes e Bases da Educação Nacional (LDB) de 1996, a educação infantil é institucionalizada como a primeira etapa da educação básica. Esses instrumentos legais provocam a discussão sobre as especificidades pedagógicas nas creches e pré-escolas e fomentam a valorização da formação de professores, tendo em vista analisar as práticas e compreender suas particularidades. De fato, a educação como direito das crianças, a responsabilidade dos sistemas de educação por esse trabalho, em vez dos órgãos de assistência somente, e a demanda de formação para a docência com as crianças pequenas provocam as universidades e as políticas de formação de professores no sentido de focalizarem as crianças como atores socias e as práticas como espaços e tempo de diálogo que dilata as experiências culturais.

Kramer (2002) enfatiza a formação como direito dos profissionais de educação infantil, afirmando que a história contada e a prática refletida são as substâncias vivas dessa formação. Assim, contrapõe-se aos modelos informativos e prescritivos de formação docente. Enfatiza a importância de políticas públicas de formação em que os professores não se tornem escravos de métodos ou receituários pedagógicos, contribuindo para sua profissionalização; por outro lado, ressalta a importância da formação cultural, a partir do reconhecimento da responsabilidade social sobre gerações de crianças, jovens e adultos, que, em nosso país, são reiteradamente expropriados de direitos elementares.

Gomes (2009) reitera essa visão, a partir das reflexões e narrativas de estagiários de Pedagogia e professores regentes, em um processo de pesquisa-formação. 
A autora afirma que a formação de professores de educação infantil envolve constituição de pertencimento institucional, cuidado, reconhecimento, socialização profissional, contribuindo para enfrentar o desafio da construção da identidade do professor:

\begin{abstract}
[..] a ambiguidade de papéis inerentes ao exercício profissional de educação e cuidado de crianças pequenas em creches e pré-escolas reforça a ideia de que o apoio a processos de trabalho coletivos e reflexão permanente sobre as teorias subjacentes às práticas, aliada à problematização destas últimas, contribuem para romper com algumas práticas cristalizadas. (GOMES, 2009, p. 64)
\end{abstract}

Kishimoto (2002, p. 110) dialoga com essa compreensão, afirmando a urgência na superação da tradição verbalista e disciplinar da academia. A autora explicita que, se a criança apreende o mundo de modo integrado, a formação de profissionais deveria passar por processo análogo, além de favorecer experiências em contexto, na própria escola. Nesse sentido, “a pesquisa pedagógica só pode ser feita no ambiente natural da prática, não no recinto fechado da Universidade”, o que envolve aliar formação e investigação sobre a prática na construção do profissional professor da educação infantil.

Vale ressaltar que, desde a publicação, pelo Ministério da Educação, Secretaria de Educação Fundamental, Coordenação Geral da Educação Infantil (MEC/SEF/COEDI), do primeiro documento que expõe diretrizes para a formação de professores de educação infantil no Brasil, Por uma política de formação do profissional de educação infantil (BRASIL, 1994), a formação é reconhecida como direito dos profissionais, contemplando as especificidades do campo, desviando de uma preparação instrumental para o ensino fundamental e das práticas domésticas. No entanto, as iniciativas de formação ainda enfrentam a descontinuidade, dispersão, fragmentação, o que prejudica a possibilidade da prática reflexiva, da construção de coletivos fortes, da consistência dos fazeres teorizados (MICARELLO, 2013).

Campos (1999), ao discorrer sobre os desafios da formação de professores das crianças de 0 a 10 anos no Brasil, enfatiza quatro aspectos. Primeiramente, o equacionamento do peso que se deve dar à formação prática e à formação teórica, entre a imagem do professor artesão e do professor liberal, formado na universidade. O segundo aspecto diz respeito à importância do conhecimento dos conteúdos do ensino e do conhecimento dos alunos e de como eles aprendem. No caso da educação infantil - na medida em que o trabalho não é centrado no professor, mas nas crianças e na expansão de suas experiências culturais -, para além do saber sobre os conteúdos, é importante o conhecimento do desenvolvimento das crianças e de suas realidades socioculturais. O terceiro aspecto a ser considerado é o nível de ensino no qual se deve oferecer o curso de formação. Segundo a LDB, o ensino médio é a terceira etapa da educação básica. A formação para o magistério deveria ser pensada a partir desse nível básico, seja complementarmente ao 
ensino médio, seja em nível superior. Cada vez mais as universidades se responsabilizam por esse trabalho, o que confere aos cursos de Pedagogia novas provocações e contornos curriculares, fortalecendo a importância de programas como o Pibid, que enfoca a aprendizagem da docência e oferece inspiração para os currículos da licenciatura. Enfim, como quarto aspecto, focaliza-se a especialização por faixa etária, dentro do intervalo mais amplo do nascimento aos seis anos. Importante considerar diferenças entre as crianças pequenas, desde os bebês, tendo em vista a organização de oportunidades de aprendizagem condizentes com as suas potências e demandas.

A partir da promulgação das Diretrizes curriculares nacionais para a graduação em Pedagogia de 2006, assumindo de forma especial a formação do professor das crianças de 0 a 6 anos dentro do curso de Pedagogia, esses desafios são intensificados. Por um lado, o enfrentamento de relações verticais entre escola básica e universidade; por outro, desconstrução de relações lineares entre teoria e prática, na valorização da formação como processo reflexivo, experiência científica e cultural.

O Pibid como política pública de formação de professores, no campo da educação infantil, apresenta-se como caminho de problematização dos modelos transmissivos e hierárquicos de formação. A experiência aqui relatada constitui-se na forte relação entre formação inicial e formação continuada, permanente exercício de narrativa, registro e reflexão sobre as práticas, o que permitia redimensioná-las constantemente. A formação universitária acontece conectada com a escola, teoria e prática redimensionam-se mutuamente, saberes sobre as crianças e sobre os modos de ser professor estão em jogo, assim como a construção da identidade docente.

A seguir, como já anunciado, vamos explicitar o funcionamento do Subprojeto Pedagogia/Educação Infantil em uma universidade pública federal, mostrando como momentos de observação da prática, protagonismo das licenciandas em atividades com as crianças na escola, registros e momentos de estudo e interlocução na universidade mobilizaram a análise crítica sobre a intencionalidade pedagógica na educação infantil, a criação de práticas e como foram potencializadores de alterações nas licenciandas e nas professoras, no sentido da aprendizagem da docência.

\section{NA ESCOLA E NA UNIVERSIDADE: ESPAÇOS E TEMPOS DE ENCONTRO E ALTERAÇÃO}

O Pibid Pedagogia/Educação Infantil concretizou-se em diversos espaços de troca e de estudo. Semanalmente, cada licencianda participava em um turno (manhã ou tarde) das atividades de uma turma da educação infantil sob responsabilidade de uma supervisora em uma das escolas parceiras. Um dos objetivos dessa participação era observar as experiências, focalizando tanto as ações docentes como as ações das crianças.

Entendemos que as observações não se restringem a um olhar passivo diante das cenas em foco. No diálogo com Bakhtin (2003), consideramos esse 
espaço/tempo de observação na perspectiva de uma compreensão ativa dos processos. Para o autor:

[...] toda a compreensão da fala viva, do enunciado vivo é de natureza ativamente responsiva (embora o grau desse ativismo seja bastante diverso); toda compreensão é prenhe de resposta, e nessa ou naquela forma a gera obrigatoriamente; o ouvinte se torna falante. (BAKHTIN, 2003, p. 271, grifos do autor)

Compreender as supervisoras e as crianças em interações no cotidiano gerava interpretações, perguntas e inquietações nas licenciandas. Produzia uma atividade delas que necessitava ter espaço e tempo para ser acolhida, manifestada. Assim, tanto ao final de uma jornada na escola como em meio ao trabalho com as crianças, e especialmente nas reuniões semanais na universidade, os sentidos construídos pelas licenciandas nas observações eram discutidos e problematizados. As outras estudantes e as próprias supervisoras sempre apresentavam uma contrapalavra, uma outra possibilidade de compreender o ocorrido, que expandia a experiência de quem narrava uma situação.

Nesse plano das observações, destacava-se a aprendizagem de "ver as crianças" e seus movimentos de significação do mundo para o planejamento de situações ampliadoras de suas experiências. Essa era uma perspectiva central do trabalho formativo, apontada como desafio e conquista nos relatos reflexivos, como destacaremos mais adiante.

Como analisa Ostetto (2011, p. 87), referindo-se à experiência do estágio que se alinha com o que é experimentado no Pibid, no espaço formativo do educador da infância, é fundamental “olhar com uma pauta para as diversas manifestações infantis, enfocando os movimentos das crianças, com atenção a seus gestos, suas falas e expressões; documentar, analisar e compartilhar impressões do observado". Esse movimento justifica-se especialmente porque fundamenta escolhas que se seguirão, referentes ao planejamento do trabalho pedagógico.

No cotidiano do Pibid, os momentos na escola eram também de condução, por parte das licenciandas, de atividades planejadas anteriormente com as professoras. Nessas ocasiões, as estudantes assumiam o protagonismo da turma e coordenavam a construção de jogos, leitura literária, exploração de linguagens artísticas, organização de espaços e interação com as crianças, dentre outras situações pedagógicas. Nessas oportunidades, a “mudança de posição” provocava deslocamentos tanto nas estudantes como nas professoras, que viam a si mesmas nas ações das outras. As licenciandas traziam para o seu modo de atuar com as crianças o que compreendiam das ações docentes e as professoras elaboravam novas visões sobre si mesmas, sobre o trabalho, sobre as crianças e as próprias estudantes.

Enfim, na universidade, todo o grupo se reunia uma vez por semana por quatro horas para leitura e discussão de textos previamente lidos, tendo em vista aprofundar referenciais teóricos sobre o trabalho. Mas sobretudo para o diálogo 
sobre as observações/compreensões da semana e a exposição de práticas que tinham sido coordenadas pelas licenciandas. Do ponto de vista da fecundidade da experiência alteritária na formação, tanto na discussão das observações da semana como na exposição de práticas, organizar o vivido para apresentar ao outro fazia com que as graduandas refletissem sobre os caminhos trilhados, dando a eles novos contornos. Para comunicar ao grupo, colocavam-se de forma exterior ao que viveram na escola, experimentando o que Bakhtin (2003) identifica como exotopia, movimento de olhar de fora a experiência e, a partir do excedente de visão que essa situação provoca, construir sentidos que só desse lugar são possíveis.

Para o autor:

[...] devo entrar em empatia com esse outro indivíduo, ver axiologicamente o mundo de dentro dele tal qual ele o vê, colocar-me no lugar dele e, depois de ter retornado ao meu lugar, completar o horizonte dele com o excedente de visão que desse meu lugar se descortina fora dele, convertê-lo, criar para ele um ambiente concludente a partir desse excedente da minha visão, do meu conhecimento, da minha vontade e do meu sentimento. (BAKHTIN, 2003, p. 23)

Os momentos na escola eram de empatia com professoras e crianças, na medida em que as estudantes experienciavam a ação docente. Na universidade, era possível experimentar-se num espaço distanciado, com possibilidade de análise e produção de sentidos ou acabamentos sobre o vivido, a partir das trocas de impressões, tendo em vista a palavra do outro.

De modo particular, a metodologia de exposição de práticas promoveu aprendizagens significativas, como será mostrado adiante. Depois das sequências de atividades vividas com as crianças na escola e a partir dos registros em vídeo, foto e por escrito realizados no decorrer do processo e depois dele, as estudantes construíam um powerpoint para apresentar ao grupo na reunião geral. Discorriam sobre as etapas da experiência e sobre os efeitos nas crianças. Também justificavam teoricamente as escolhas e os caminhos seguidos. O momento de organizar o powerpoint e falar das situações da prática provocavam novas reflexões sobre as ações experimentadas.

Outro instrumento importante nesse processo foi a ata/registro dos encontros semanais na universidade. Todas as participantes revezavam-se na tarefa de anotar as discussões e redigir um texto descritivo para a leitura no encontro posterior. Após a leitura, a autora fazia alterações, a partir das contribuições do grupo. A escrita também possibilitava a (re)organização da experiência, propiciando visibilidade dos temas tratados e novas reflexões na leitura que ocorria no início do encontro seguinte. A autoria configurava-se de forma coletiva. No próximo item, alguns extratos dessas atas serão expostos tendo em vista explicitar o movimento relacional e dialógico dos encontros, além das aprendizagens concretizadas. 
Tal como afirma Ostetto (2017, p. 21), os registros escritos são textos vivos, traduzem a experiência, oportunizam comunicação e troca, constituem espaços de construção de autorias, afirmando o papel do professor como narrador. Portanto, são caminhos férteis para a formação de professores num viés reflexivo, na medida em que "registrar é escrever sobre a prática, tecer memória da experiência com anotações que serão matéria de análise e reflexão”.

Podemos dizer que a análise das práticas com continuidade e sistematicidade, tal como ocorria nesta experiência, constitui o que Zeichner (2010, p. 1) chama de terceiro espaço ou espaço híbrido na formação de professores, no qual "conhecimento empírico e acadêmico e o conhecimento que existe nas comunidades estão juntos de modo menos hierárquico...”. Não se tratava de um terceiro espaço físico, mas de um espaço de troca, de centralidade nas práticas. A partir da participação das estudantes na escola básica, da experiência das docentes regentes e do movimento reflexivo por dentro das práticas, ampliavam-se as conexões entre a escola, o fazer pedagógico que nela ocorre e a formação docente.

\section{NA EXPERIÊNCIA FORMATIVA, APRENDIZAGENS SOBRE OS SENTIDOS DA DOCÊNCIA NA EDUCAÇÃO INFANTIL}

Ao longo do trabalho formativo, era comum as professoras supervisoras nomearem a inserção no Programa como uma "chance para respirar”. Sair da escola ou deslocar-se do lugar da relação com as crianças para pensar sobre ela, na medida em que abria espaços novos, provocava mudanças, novos olhares, reconhecidos com a qualidade de "respiração". Frequentemente, as professoras afirmavam que estar no Pibid era sair da "zona de conforto", dando visibilidade ao trabalho delas com as crianças, permitindo que pudessem ser interrogadas.

Por outro lado, as professoras também afirmavam o quanto a experiência do Pibid diferia da formação que tiveram na licenciatura. De modo geral, relatavam a passagem por estágios em que eram observadoras passivas e concretizava-se uma concepção de educação infantil preparatória, instrumental, focada na modelagem de habilidades nas crianças. A revisão dessas visões acontecia na experiência de formação continuada e fortalecia-se na oportunidade de estudo e troca no Pibid, nos momentos em que suas ações com as crianças eram focalizadas e ressignificadas, para elas mesmas. Em consonância com Tardif (2014), a experiência na prática e o Programa oportunizavam a perspectiva crítica e a "retradução" da formação inicial delas.

Para o autor:

A experiência provoca um efeito de retomada crítica (retroalimentação) dos saberes adquiridos antes ou fora da prática profissional. Ela filtra e seleciona os outros saberes, permitindo assim aos professores reverem seus saberes, julgá-los e avaliá-los. (TARDIF, 2014, p. 53) 
Uma das questões vividas de modo intenso era a aprendizagem de uma intencionalidade pedagógica que passa pela atenção às ações das crianças, ou seja, um novo modo de compreender o ensino. O que é ensinar na educação infantil? Era comum as licenciandas indagarem sobre o conteúdo, as disciplinas, o planejamento fechado e focado nos produtos. Tornava-se um desafio explicitar uma prática centrada nas crianças, como propõem as Diretrizes curriculares nacionais da educação infantil (BRASIL, 2009), no desvio de perspectivas adultocêntricas ou instrucionais; ou seja, considerar o ensino, tal como indica Tardif (2014, p. 13), como "agir com outros seres humanos", um modo de relação social atravessado pelo reconhecimento de que alguém ensina e outro aprende, em perspectivas negociadas tacitamente. Neste caminho, o conhecimento não é uma substância, algo fechado, pré-determinado necessariamente, mas manifesta-se através de relações complexas entre quem ensina e quem aprende.

Para Roldão (2007, p. 94), o conceito de ensinar, próprio da profissão docente, é atravessado por uma tensão profunda “entre o professar um saber e o fazer outros se apropriarem de um saber - ou melhor - fazer aprender alguma coisa a alguém”. Neste caminho, é importante localizar um conhecimento profissional específico que exige o reconhecimento da necessidade de uma formação própria. Quando nos referimos à educação infantil, essa tensão assume contornos peculiares, tendo em vista que o trabalho pedagógico é focado nas crianças e o papel do professor coloca-se como ampliador de suas experiências culturais.

Rocha (2001) discute as especificidades de uma pedagogia da educação infantil a partir do foco nas crianças e nas relações educativas e não no aluno em processos de ensino que se configuram na aula, numa versão transmissiva, o que não significa que não haja ensino na educação infantil e nem que os conhecimentos legitimados não estejam em cena no processo educativo:

[...] a dimensão que os conhecimentos assumem na educação das crianças pequenas encontra-se extremamente vinculada aos processos gerais de constituição da criança: a expressão, o afeto, a sexualidade, a socialização, o brincar, a linguagem, o movimento, a fantasia, o imaginário, ou seja... as suas cem linguagens. (ROCHA, 2001, p. 31)

Essas ideias desdobram-se nas definições das Diretrizes curriculares nacionais da educação infantil (BRASIL, 2009). De acordo com as Diretrizes, o currículo da educação infantil é concebido como um conjunto de práticas que buscam articular as experiências e os saberes das crianças com os conhecimentos que fazem parte do patrimônio cultural, artístico, ambiental, científico e tecnológico da humanidade (BRASIL, 2009). Ou seja, o compromisso do professor é promover oportunidades para as crianças se apropriarem da cultura, o que se desvia de ações informativas, transmissivas. Trata-se de saber escutar as crianças, organizar materiais e atividades que ampliem seus interesses e experiências, na perspectiva das diferentes linguagens e áreas do conhecimento. 
Num processo de pesquisa-formação com professores de educação infantil, a partir de suas narrativas e experiências, Micarello (2006) identifica como saberes de referência na constituição da identidade docente o saber brincar, saber narrar e saber acolher, que desafiam as realidades institucionais geralmente marcadas pela fragmentação do tempo e das relações interpessoais. Ser professor de educação infantil implica a disponibilidade corporal-afetiva do adulto, a valorização do brincar, a escuta e consideração das linguagens das crianças.

O campo da Pedagogia da Infância ou Pedagogia da Educação Infantil, que se constitui no Brasil desde o final da década de 90 do século XX, compromete-se com as ideias da participação e da ação das crianças na construção de conhecimentos sobre si mesmas e sobre o mundo (ROCHA, 2001; OLIVEIRA-FORMOSINHO, 2007). Quando o sujeito da aprendizagem é a criança de 0 a 6 anos, é importante considerar as possibilidades de ação, relação e agência social, no contraponto de uma visão de criança passiva, receptora e reprodutora. Trata-se de focalizar o interesse e a ação da criança para além do conteúdo ou do currículo prescrito. Para tal, constituem-se como vetores: a organização de ricos contextos físicos de aprendizagem, isto é, reflexão sobre a potência pedagógica dos tempos, espaços e materiais; contextos sociais diversos, com oportunidade de escuta e observação ativa das crianças. Nessas situações, o ponto final da aprendizagem não está pré-fixado antes da relação com as crianças, mas o papel ativo e relacional do professor é central.

É papel do professor promover a entrada das crianças em novas semióticas, provocar estranhamento e tensão entre saberes anteriores e experiências presentes, a partir da compreensão da aprendizagem como problematização e não somente reconhecimento de um mundo já dado. Nessa perspectiva, ensinar é apontar numa direção, en-signar, organizar possibilidades de encontros das crianças com os signos, na medida em que compreendemos que aprender é interpretar signos, verbais e não verbais (KASTRUP, 2001).

De fato, diante dessa perspectiva, quando compreendemos que não é o objetivo da educação infantil ensinar conteúdos, ensinar algo pré-determinado, a formação de professores também precisa ser problematizada. Se consideramos a multiplicidade de aspectos, saberes e experiências em jogo na relação da criança com a cultura e o conhecimento, quais domínios devem fazer parte dessa formação?

Na qualificação do conhecimento próprio da profissionalidade docente, Roldão (2007) localiza o desafio da contraposição tanto em relação a uma discursividade humanista, como no que diz respeito a uma especificação operativa. Não se trata nem da romantização da ação dos professores, nem da redução dela a uma dimensão técnica. No caminho da clarificação dessa profissionalidade, a autora identifica a sua complexidade ligada à miscigenação de elementos pessoais e profissionais no desempenho docente; também ligada ao nascimento da atividade profissional docente antes que sobre ela se produzisse conhecimento sistematizado, o que lhe confere certa "praticidade" que, se não for teorizada, não se converte em ação profissional. 
Nessa perspectiva, a autora afirma que a formalização do conhecimento profissional ligado ao ato de ensinar

[...] implica na consideração de saberes de vários tipos, passíveis de diversas formalizações teóricas-científicas, científico-didáticas, pedagógicas (o que ensinar, como ensinar, a quem e de acordo com que finalidades, condições e recursos), que, contudo, se jogam num único saber integrador, situado e contextual - como ensinar aqui e agora -, que se configura como prático. (ROLDÃO, 2007, p. 98)

Essa compreensão demanda a reconfiguração do que se entende como relação teoria-prática, na contramão do aplicacionismo ou do academicismo teórico. A referida autora afirma que a função de ensinar é socioprática, mas requer um saber teorizador, compósito e interpretativo; ou seja, liga-se a uma prática teorizada, discutida coletivamente, reconceitualizada nas situações reais (ROLDÃO, 2017).

A formação de professores no campo da educação infantil enfrenta esses desafios de forma contundente, como já foi exposto. A informalidade, a perspectiva doméstica e custodial da relação institucional com as crianças ainda atravessa o trabalho pedagógico e provoca a formação de professores no sentido de tornar-se espaço e tempo de construção de uma intencionalidade pedagógica refletida, a partir da prática, mas não a ela restrita.

Nesse panorama, colocam-se as questões: como ensinar a licenciandas em formação inicial as peculiaridades de uma docência onde é central escutar as crianças, mas onde isso se coloca num lugar profissional e não do improviso? Como compreender a importância da abertura aos sentidos das crianças, mas também da ação provocadora e intencional do professor? Como compreender o ensino a partir do movimento de aprendizagem e desvendamento do mundo por parte das crianças?

Escutar as crianças é uma metáfora para a atenção a todos os seus sentidos, o que implica a escuta não só do que dizem, mas a observação de seus movimentos, ausculta de suas ações, ao mesmo tempo em que se registram e planejam novas situações instigadoras, o que se configura como mobilizar o ensino. O desafio que se coloca é formar pedagogos professores para ocupar um papel propositivo e, ao mesmo tempo, dialógico com as crianças, o que envolve: organizar contextos promotores da expansão do que as crianças sabem, perguntam, daquilo por que se interessam; provocar experiências de problematização e não somente reconhecimento do mundo.

Nessa trilha, nas experiências do Pibid, o registro por parte das professoras de suas experiências como formadoras com as licenciandas e com as crianças abria possibilidades de compreensão e objetivação do que é pedagógico na educação infantil, dos caminhos da ação docente, das possibilidades da formação na prática. Algumas situações do contexto formativo do Pibid/Pedagogia/Educação 
Infantil mostram as peculiaridades da formação a partir da prática que é narrada, registrada e, assim, ressignificada/teorizada no coletivo.

Segue abaixo um relato reflexivo da professora Kelsiane e as reflexões que gerou no grupo:

\begin{abstract}
Certa vez estávamos na roda para planejar o dia e apresentar algumas propostas que pensamos para o grupo de crianças de quatro anos [...] quando uma aranha-bebê passou desengonçada pelo meio da roda. Uma criança apontou para o "miserável" bichinho que, obviamente, despertou interesses e curiosidades. Rapidamente o grupo se voltou para a aranha e, com postura investigativa, começaram a fazer perguntas e suposições sobre o inseto. Troquei olhares com as pibidianas e me voltei para o bichinho, entrando no jogo de perguntas e devolvendo algumas para o grupo a fim de perceber os interesses e os rumos que aquele encontro inesperado poderia nos levar. As propostas que trouxera, guardei para outro momento, retomamos a roda, e aproveitamos para ouvir as crianças sobre os animais de estimação e/ou preferidos delas e os afetos que suscitam. (Professora-supervisora Kelsiane/2016; grifos da autora)
\end{abstract}

A partir da discussão dessa e de outras situações, as licenciandas e as próprias professoras davam-se conta com mais clareza dos saberes profissionais envolvidos na prática docente: acolher, narrar, considerar as crianças, levantar com elas saberes e hipóteses sobre experiências compartilhadas, suscitar diálogos e trocas de pontos de vista. As estudantes espantavam-se com os modos de fazer acontecer o encontro das falas no grupo e fortaleciam nas supervisoras a identidade de professoras da educação infantil. A troca de olhares na roda pontua cumplicidade na identificação do momento em que algo se alterava e provocava nelas também alteração.

A seguir, apresentamos extratos de duas atas/registros de reuniões na universidade, onde se apresenta a aprendizagem da docência na observação ativa das crianças e da professora. Também se evidencia como vai sendo compreendido o movimento de planejar a partir da consideração das ações das crianças. Esta situação aconteceu na turma da professora Kelsiane com crianças de três e quatro anos:

Cláudia/licencianda trouxe como destaque a experiência que vivenciou de uma brincadeira simbólica sendo construída pelas crianças. Com toda receptividade, criatividade e imaginação, as crianças insistiram em preparar uma refeição apetitosa para ela. Assim, com toda gesticulação e empolgação, as crianças se empenhavam calorosamente em seus feitos culinários e, com a massinhas de modelar da cor azul 
claro, prepararam arroz, estrogonofe, lagosta e panquecas. Neste cenário, Claudia relata que a professora Kelsiane teve a sensibilidade de trazer como proposta de todos realizarem panquecas na próxima semana para o almoço. (Ata do encontro de 19 set. 2016)

Claudia falou sobre a experiência culinária [...]. Ficou encantada com a participação das crianças na preparação do alimento. O processo contou com a leitura da receita, a mistura dos ingredientes, transformação das panquecas líquido/sólido, passar manteiga na frigideira, o chiado da frigideira, tudo isso foi apreciado pelas crianças. E não faltou a brincadeira de jogar a panqueca para cima. (Ata do encontro de 26 set. 2016)

Nas reuniões na universidade, esclarecia-se que a intencionalidade pedagógica na educação infantil passa por certa atencionalidade e pela capacidade de resposta da professora aos movimentos das crianças. Trata-se de uma intencionalidade dialógica (GUIMARÃES; GUEDES; BARBOSA, 2013).

No contexto relatado, no "acabamento" das situações apresentadas, era muito importante nomear o que as crianças estavam aprendendo ou o que a professora estava fazendo-as aprender de forma não diretiva. Nesse caso, estava em jogo a aproximação do gênero textual receita, a transformação dos ingredientes e, sobretudo, a participação social; ou seja, num momento posterior, distante da prática, mas a partir dela, era possível compreendê-la e teorizá-la, na análise, tal como sugere Roldão (2007), do que se fez, por que se fez, como se fez.

Na mesma trilha, segue outro registro que mostra a apropriação das licenciandas em relação ao planejamento de uma situação de aprendizagem onde tornava-se presente o envolvimento e participação das crianças. Trata-se da turma de crianças de cinco anos da professora Vera, num projeto sobre Zeus e a mitologia grega:

Tais falou com entusiasmo da sua participação na atividade proposta pelas crianças de confecção de dois mapas para saírem à procura de mais uma pista de Zeus. Falou da aventura, da brilhante sugestão de dividir a turma em dois grupos para percorrerem uma área maior em menos tempo, dos desenhos com os locais a serem investigados, da organização das figuras no papel quarenta quilos, da numeração sequenciada do trajeto, etc... Neste momento, a coordenadora nos convidou a pensar quais eram os conhecimentos envolvidos nessas atividades. Então, listamos: autonomia, criação, autoria, leitura e escrita, exercício da interpretação, noções espaciais, o mapa como registro, solução de problemas, construção de hipóteses de investigação, entre outros. (Ata do encontro de 26 set. 2016) 
O relato de observação das práticas gerava teorização do vivido, explicitação das camadas de aprendizagem experimentadas com as crianças (áreas do conhecimento em foco, diferentes linguagens em desenvolvimento). Era comum, depois dos relatos, a pergunta: qual foi o papel compreensivo e ativo da professora? O que e como as crianças aprenderam?

Abaixo, na apresentação de um planejamento, era possível colher sugestões e alterar o plano em função da participação de todos. O coletivo como lugar de planejamento e exposição de perspectivas ampliava as possibilidades e ações com as crianças. A dimensão alteritária da formação apresentava-se também nos processos a construir concretamente. Essa situação refere-se ao trabalho com uma das professoras na sala de leitura da escola que recebia as crianças de 0 a 6 anos:

Adriane começou a apresentar o planejamento do grupo da Priscila. Ela explicou que o planejamento foi feito em cima do livro O Presente da Vovó Loba, em seguida leu os objetivos que são ampliar o repertório literário do grupo, despertar nas crianças o gosto pela leitura, favorecer o momento de socialização e contribuir para o incremento da imaginação das crianças. Adriane relatou que a licencianda Lorraine teve a ideia de fazer do momento de chegada do livro, uma ocasião especial. A atividade seria a chegada do livro pelo sedex e, em seguida, a leitura do livro em roda; depois haveria uma conversa em busca das opiniões das crianças sobre o que seria o presente da vovó loba. Após a conversa e as hipóteses levantadas pelas crianças, seria feita uma carta em conjunto para enviar para a vovó e essa carta seria de fato enviada nos correios e na semana seguinte chegaria a resposta $[\ldots]$

Após a leitura do planejamento, surgiu a ideia de que a construção da carta seja feita de maneira coletiva, que enquanto uma das licenciandas escrevem em letra bastão, as crianças ditam o conteúdo da carta. As crianças podem também produzir desenhos para enviar para a vovó loba. Surgiu ainda a ideia de solicitarem autorização aos responsáveis para levarem as crianças para a agência dos correios para postar a carta; talvez o grupo do Pedro II empreste o uniforme dos correios... (Ata do encontro de 27 mar. 2017)

Outras cenas registradas nas atas, a partir do relato das licenciandas, mostram o movimento de aprendizagem da docência. A observação dos sentidos que as crianças produzem nas interações mostrava-se fundamental na construção de uma prática dialógica, em que o "ensinar" acontece a partir do movimento de aprendizagem das crianças. No entanto, estava sempre presente a indagação: 
quando e como intervir? Como ampliar os sentidos das crianças sem sermos muito diretivos, mas implicados com o interesse e envolvimento delas?

Adriane fala de uma vivência no pátio da escola, onde as crianças exploravam todo o ambiente também com bastante autonomia. Umas brincavam no parquinho, outras subiam na árvore, outro grupo descobriu uma formiga e começou a questionar sobre o quê a formiga comia. Daí veio a ideia de um menino: dar bolo para a formiga. Eles prenderam uma formiga dentro de um caminhão de brinquedo; quando ela ia saindo, ficavam eufóricos para prender novamente [...] Ficamos pensando sobre o papel do professor na observação desta cena [...] quando se vê um grupo de crianças de 3, 4,5 anos andando numa linha ou em fila fica muito claro que ali tem um professor, mas quando se você vê um grupo de crianças soltas brincando num pátio não fica claro que ali tem um professor. (Ata do encontro de 3 abr. 2017)

A pibidiana Milena contou que as crianças queriam brincar de castelo e que a professora Kelsiane levou uma caixa de papelão para o pátio para que explorassem. Um menino de outra turma se aproximou e pediu para brincar. Uma criança da turma da Kel disse que ele era "muito preto" e que por isso não podia brincar. A licencianda Ingrid foi quem presenciou a situação e sinalizou para Kelsiane, que se aproximou e interviu perguntando o que estava acontecendo. Para a professora, a criança não repetiu a afirmação que fizera antes. Kelsiane acolheu o menino da outra turma, ajudando-o a introduzir-se na brincadeira. Milena continuou contando que a criança quis sair do castelo, alegando que estava muito cheio. Outras pibidianas que atuam na turma lembraram de outros episódios parecidos no ano anterior como, por exemplo, a rejeição de bonecas negras. As pibidianas disseram ainda que pretendem focar o próximo planejamento nas questões que dizem respeito às diferenças étnico-raciais. A coordenadora comenta que existem pelo menos dois caminhos para abordar a questão: a valorização da cultura negra ou africana (brinquedos, materiais e brincadeiras, são exemplos) e a intervenção direta, objetiva, em rodas e nas situações como a que ocorreu. Taís falou sobre a experiência na outra escola com o livro As tranças de Bintou e contou como usou o próprio cabelo para fazer intervenções nas situações de preconceito. (Ata do encontro de 28 ago. 2017)

Milena relata sobre o planejamento que vamos iniciar com uma cesta com elementos africanos, a boneca abayomi, 
livros com personagens negros, instrumentos musicais. No segundo momento, faremos a leitura de um livro escolhido pelas crianças. No terceiro momento, estamos em dúvida se colocamos as crianças para tirar fotos dos tipos de cabelos deles, ou o salão na sala, ou a oficina da boneca abayomi, a decisão vai depender da acolhida e interação com o material inicialmente exposto. (Ata do encontro de 25 out. 2017)

Nos registros acima, tanto quando a professora leva a caixa de papelão para incrementar a ideia das crianças de construir castelos, como quando as licenciandas pensam em estratégias para lidar com situações de preconceito e racismo na turma, que aparecem nas brincadeiras, percebemos o caráter dialógico do planejamento, além de uma possibilidade de ensino que não passa por "dar aula" sobre um tema, mas por ampliar o universo de significações das crianças sobre os temas emergentes.

O mesmo ocorre na situação relatada a seguir:

\begin{abstract}
A pibidiana Taís observou que constantemente as crianças brincavam de médico, realizando partos e consultas nos cantos da sala. Tal observação culminou na realização do planejamento de um espaço na sala de referência das crianças que potencializasse o brincar. Assim, através de escuta e olhar atento das pibidianas e da Professora Vera, o grupo construiu na sala um espaço de consultório médico. Levaram instrumentos e aparelhos reais para o espaço, como por exemplos, chapas de raio-x, caixas de remédio, ataduras, etc. (Ata do encontro de 4 dez. 2017)
\end{abstract}

Nessa situação, o espaço é compreendido como interlocutor das crianças (GANDINI, 1999). As ações da professora e das licenciandas mostram que a docência na educação infantil se concretiza principalmente de modo indireto; ou seja, o planejamento de ambientes instigadores, a inserção de novos materiais, o relevo dado às situações de faz de conta como espaços/tempo de ampliação de experiências e aprendizagem colocam-se como ações docentes intencionais, propositivas, mas não diretas ou sobre as crianças.

A seguir, apresentamos o registro de uma ata em que podemos perceber, no momento de exposição de práticas, como as licenciandas vão se dando conta das aprendizagens que ocorrem nas interações e como vão percebendo suas próprias ações ao colocarem-nas em discurso, para o outro:

As licenciandas do grupo da Vera relatam as etapas das atividades no Projeto Lobo com as crianças de 3 anos. $\mathrm{Na}$ primeira etapa, as licenciandas colocaram pegadas fictícias do lobo no chão, tendo em vista aguçar a imaginação das 
crianças [...] no final das pegadas, colocaram uma caixa (de pizza) com um livro e uma carta dentro dela. O livro era "Este é o lobo" de Alexandre Rampazo. As crianças, então, seguiram as pegadas e encontraram a caixa. Quando abriram, as pibidianas leram a carta em roda. Taís afirma que ao assistir ao vídeo desse momento, percebeu o quanto ela "corta" as pessoas, não abre muito espaço para as crianças falarem de suas impressões. Essa foi uma crítica da sua prática. Ela refletiu e afirmou que necessita mudar [...]

Durante a leitura do livro de imagens, as crianças gostaram bastante, pois as ilustrações são muito interessantes e instigadoras. Surgiram algumas falas das crianças: "O lobo era mau?"; "ele comia as pessoas?”; "o lobo estava ficando pequeno"; "o que aconteceu com o chapeuzinho? ela foi comida?”; [...] "ele comeu muita coisa e está diminuindo?”; “o lobo não quer brincar porque ele é mau?".

Vera/professora pergunta: "Por que ele é mau"?

As crianças responderam: "porque ele tem um olhar mau, um olho mau".

Depois as crianças foram para o lado de fora e encontraram uma caixa de areia deixada ali por outro grupo, ficaram perguntando se era a casa do lobo, se ele ficava ali, ficaram seguindo as pegadas da brincadeira anterior. Relacionavam o que tinham vivido com a nova situação. Então, Tais e Andressa propuseram às crianças fazerem uma carta com as perguntas para o lobo. As crianças faziam a pergunta e elas escreviam na carta. Abaixo, algumas indagações das crianças.

Mariana: Boa tarde, seu lobo; essa areia é sua cama de noite para você dormir e brincar?

Miguel: Seu Lobo, você comeu o carteiro, vestiu a roupa dele para nos entregar a carta?

Maria Clara: Seu Lobo, você vai parar de comer a pizza?

Nathalia: Seu Lobo, quanto você calça?

(Ata do encontro de 3 abr. 2017)

Na reunião posterior, indagamos sobre o lugar do adulto, o lugar das crianças e do conhecimento. Destacou-se a análise da ação problematizadora da professora quando, diante das falas das crianças, que ressaltam a maldade do lobo, pergunta “por que ele é mau?”. Também a proposta de escreverem cartas com perguntas para o lobo instaurou uma iniciativa propositiva a partir da observação ativa das crianças. A pergunta, tanto da professora como das crianças, indica a importância da aprendizagem de lidar com essa abertura. Por um lado, o adulto que espera a resposta da criança, desviando da simples aquiescência diante de suas impressões. Por outro lado, a promoção da ação indagadora das próprias 
crianças. É importante perceber esses movimentos como oportunidades para que as crianças distendam seus discursos.

Nessa cena, percebemos também o trabalho com o gênero textual carta, as diferentes possibilidades de produção por parte das crianças, o texto oral, o texto escrito (em que as graduandas eram escribas, mas com autoria das crianças), a brincadeira de faz de conta como componente do trabalho.

Também ações como a construção das pegadas, a colocação no pátio da caixa de pizza com o livro dentro, a sugestão de "escrever uma carta para o lobo" mostram a aprendizagem das licenciandas de aspectos importantes da docência na educação infantil, ou seja: a ludicidade; o movimento de provocar a surpresa, a indagação, o encantamento; a ação propositiva dialógica, que parte da observação das crianças e compromete-se com sua ampliação.

Por fim, nas discussões, as professoras também iam se dando conta de suas práticas e de novas possibilidades de entendimento do que é pedagógico no cotidiano. Tal como sugere Nóvoa (2013), reflexão em equipe, a prática e a profissão como pontos de partida, horizontalidade entre o professor da universidade e o professor da educação básica eram aspectos e movimentos que qualificavam a formação de todos os envolvidos.

\section{CONSIDERAÇÕES FINAIS}

Neste trabalho, explicitamos a experiência formativa no Pibid Pedagogia com ênfase na educação infantil numa universidade pública federal entre os anos de 2016 e 2017, sublinhando a aprendizagem da docência nesse contexto. Focalizamos o processo como oportunidade de problematização da prática pedagógica, em novas articulações entre teoria e prática, na contraposição de hierarquias e valorização de um polo em detrimento do outro. Também discutimos a formação no movimento de construção de uma profissionalidade docente, num contexto dialógico e coletivo, onde todas - graduandas e professoras experientes - estavam em movimento de aprendizagem.

Destacamos que a reflexão sobre a formação de professores no âmbito da educação infantil desdobra-se na discussão sobre a identidade da docência nesse contexto, o que é especialmente relevante, tendo em vista a frágil consideração da profissionalidade dos professores na educação as crianças de 0 a 6 anos, que ainda é associada às práticas domésticas ou compreendida como arremedo ou simplificação das práticas do ensino fundamental.

Também destacamos que a metodologia de formação constituída no Programa concretizou-se a partir de uma prática de interlocução, em que os discursos de professores regentes e licenciandas tensionavam-se ou complementavam-se, construindo espaços de constituição de sentidos sobre a prática pedagógica. Esse processo indica a importância da interlocução como metodologia formativa, no contraponto de práticas enciclopedistas e instrucionais de formação.

Noutro prisma, caminhamos na linha do que propõe ANDRÉ (2016, p. 32), quando afirma que a formação para um novo desenvolvimento profissional 
"baseia-se na concepção de um professor pesquisador, que vai se orientar para compreender as teorias implícitas na ação”, fundamentando-as, revisando-as, reconstruindo-as. Trata-se de perguntar-se sobre o porquê das suas ações, desnaturalizando-as, problematizando-as. No processo aqui relatado, essa situação presentificou-se tanto para as licenciandas em formação inicial como para as professoras, tendo em vista a constante indagação sobre quais conhecimentos estavam em jogo e qual a qualidade do ensino e da intencionalidade pedagógica envolvidas nas ações desenhadas e concretizadas com as crianças.

Convém sublinhar que esse movimento sintoniza-se com o que Tardif (2014, p. 111) nomeia como a construção de uma "epistemologia da prática docente”, ou seja, "um trabalho que tem como objeto o ser humano e cujo processo de realização é puramente interativo”, baseado fortemente no saber experiencial, sincrético, plural e heterogêneo que compõe a prática dos professores.

É importante considerar que os efeitos formativos do Pibid, como política pública federal de formação de professores de caráter pontual, podem mobilizar licenciaturas, de modo particular a Pedagogia, a construir espaços horizontais, permanentes e efetivos de discussão de práticas e teorização de fazeres. Como sugerem Pimenta e Lima (2011), os estágios podem ser oportunidade de aprendizagem na prática, formação de todos os envolvidos, a partir da valorização do lugar de onde os professores falam, na interação ente os cursos de formação e a escola.

No campo de trabalho aqui discutido, a observação ativa, o planejamento e a exposição de práticas na relação entre licenciandas e supervisoras/professoras regentes foram caminhos metodológicos fecundos na mobilização de experiências formativas atentas ao que produzem as crianças e ao papel ativo do professor.

Neste panorama, a contribuição de Bakhtin (2003) também é relevante quando o autor afirma o entrelaçamento entre o conhecimento, o agir ético e a arte na consideração do humano. Para o autor, arte e vida não são a mesma coisa, mas devem tornar-se algo singular na experiência de cada um, na unidade da responsabilidade. Entendemos que a educação e a formação de professores envolvem um agir ético, criativo e implicado com a vida dos adultos e crianças, agir coletivo, dialógico e responsável. Nesse agir, o conhecimento se produz como processo de criação de caminhos, criação de práticas. Arte, criação, conhecimento e vida estão imbricados nesse processo.

No que se refere à educação infantil, essa reflexão é importante, tendo em vista a urgência de enfrentar formas de trabalho pedagógico historicamente construídas; ou seja, os modelos domésticos, de cuidados automatizados e serializados, por um lado, e os modelos instrucionais, preparatórios, de outro lado. Como afirma Micarello (2005), em pesquisa no campo da formação de professores de educação infantil, é fundamental repensar as relações entre teoria e prática na formação, constituindo na formação inicial momentos em que as práticas sejam focalizadas, provocando reformulação delas e reconstrução das teorias, considerando condições concretas de trabalho crítico e reflexivo, além do foco na infância como construção social. Trata-se de criar um agir formativo ético, implicado 
com o coletivo, compromissado com as crianças, promotor da autoria e autonomia dos professores, ao mesmo tempo que com o conhecimento já produzido.

O Pibid/Pedagogia/Educação Infantil, ao proporcionar dois anos de experiência na formação de cada licencianda, mergulhada na prática, e dois anos de formação para as professoras, tendo em vista enunciar e refletir sobre suas práticas, produziu, nos espaços interlocutivos e reflexivos, alteração dos fazeres com as crianças, objetivação desses fazeres, ampliação de experiências e qualificação do trabalho pedagógico.

Nesse caminho, clarifica-se o que é pedagógico na educação das crianças de 0 a 6 anos e a qualidade da docência nesse contexto. No desvio das práticas instrucionais e transmissivas, a escuta das crianças, a valorização de diferentes manifestações da linguagem no cotidiano, o planejamento de ações dialógicas e ampliadoras de suas experiências, o espaço e o contexto como formadores emergem como pistas de uma ação indireta mas intencional do professor.

\section{REFERÊNCIAS}

ANDRÉ, Marli (org.). Práticas inovadoras na formação de professores. Campinas: Papirus, 2016.

BAKHTIN, Mikhail. Estética da criação verbal. São Paulo: Martins Fontes, 2003.

BRASIL. Constituição da República Federativa do Brasil. Brasília, DF: Senado, 1988.

BRASIL. Ministério da Educação. Secretaria de Educação Fundamental. Coordenação Geral da Educação Infantil. Por uma política de formação do profissional de educação infantil. Brasília: MEC/SEF/Coedi, 1994.

BRASIL. Ministério da Educação. Lei n. 9.394, de 20 de dezembro de 1996. Lei de Diretrizes e Bases da Educação Nacional. Brasília, 1996.

BRASIL. Ministério da Educação. Conselho Nacional de Educação. Resolução 1/2006. Institui Diretrizes Curriculares Nacionais para o Curso de Graduação em Pedagogia, licenciatura. Brasília, 2006.

BRASIL. Ministério da Educação. Secretaria da Educação Básica. Diretrizes curriculares nacionais para a educação infantil. Brasília: MEC/SEB, 2009.

CAMPOS, Maria Malta. A formação de professores para crianças de 0 a 10 anos: modelos em debate. Educação e Sociedade, Campinas, v. 20, n. 68, p. 126-142, dez. 1999.

GANDINI, Lella. Espaços educacionais e de envolvimento pessoal. In: EDWARDS, Carolyn; GANDINI, Lella; FORMAN George. As cem linguagens da criança: a abordagem de Reggio Emilia na educação da primeira infância. Porto Alegre: Artes Médicas, 1999. p. 145-158.

GATTI, Bernardete A. Questões: professores, escolas e contemporaneidade. In: ANDRÉ, Marli (org.). Práticas inovadoras na formação de professores. Campinas/SP: Papirus, 2016.

GOMES, Marineide de Oliveira. Formação de professores na educação infantil. São Paulo: Cortez, 2009.

GUIMARÃES, Daniela; GUEDES, Adrianne Ogeda; BARBOSA, Silvia Neli. Cuidado e cultura: propostas curriculares para o trabalho com crianças de até três anos. In: KRAMER, Sonia; NUNES, Maria Fernanda; CARVALHO, Maria Cristina. Educação infantil: formação e responsabilidade. Campinas: Papirus, 2013.

KASTRUP, Virginia. Aprendizagem, arte e invenção. Psicologia em Estudo, Maringá, v. 6, n. 1, p. 17-27, jan./jun. 2001. 
KISHIMOTO, Tizuko Morchida. Encontros e desencontros na formação de profissionais da educação infantil. In: MACHADO, Maria Lucia (org.). Encontros e desencontros em educação infantil. São Paulo: Cortez, 2002. p. 107-116.

KRAMER, Sonia. Formação de profissionais de educação infantil: questões e tensões. In: MACHADO, Maria Lucia (org.). Encontros e desencontros em educação infantil. São Paulo: Cortez, 2002. p. 117-132.

KUHLMANN JR., Moysés. Infância e educação infantil: uma abordagem histórica. Porto Alegre: Mediação, 1998.

MICARELLO, Hilda Aparecida Linhares da Silva. Formação de professores de educação infantil: sair da teoria e entrar na prática? In: KRAMER, Sonia (org.). Profissionais da educação infantil: gestão e formação. São Paulo: Ática, 2005.

MICARELLO, Hilda Aparecida Linhares da Silva. Professores da pré-escola: trabalho, saberes e processos de construção de identidade. Tese (Doutorado em Educação) - Pontifícia Universidade Católica do Rio de Janeiro, Rio de Janeiro, 2006. 212 p.

MICARELLO, Hilda Aparecida Linhares da Silva. Formação de professores da educação infantil: puxando os fios da história. In: KRAMER, Sonia; ROCHA, Eloisa Acires Candal. Educação infantil: enfoques em diálogo. São Paulo: Papirus, 2013. p. 211-228.

NÓVOA, Antonio. Nada substitui um bom professor: propostas para uma revolução no campo da formação de professores. In: GATTI, Bernardete A. et al (org.). Por uma política nacional de formação de professores.

São Paulo: Unesp, 2013.

OLIVEIRA-FORMOSINHO, Julia. Pedagogia(s) da infância: reconstruindo uma práxis de participação. In: OLIVEIRA-FORMOSINO, Julia; KISHIMOTO, Tizuko M.; PINAZZA, Monica. Pedagogia(s) da infância: dialogando com o passado, construindo o futuro. Porto Alegre: Artmed, 2007. p. 13-36.

OSTETTO, Luciana Esmeralda. Deslocamentos, aproximações, encontros: estágio docente na educação infantil. In: GOMES, Marineide de Oliveira (org.). Estágios na formação de professores. São Paulo: Edições Loyola, 2011.

OSTETTO, Luciana Esmeralda. Registros na educação infantil: pesquisa e prática pedagógica. São Paulo: Papirus, 2017.

PIMENTA, Selma Garrido; LIMA, Maria Socorro Lucena. Estágio e docência. São Paulo: Cortez, 2011.

ROCHA, Eloisa Acires Candal. A pedagogia e a educação infantil. Revista Brasileira de Educação, Rio de Janeiro, n. 16, p. 27-34, jan./fev./mar. 2001.

ROLDÃO, Maria do Céu. Função docente: natureza e construção do conhecimento profissional. Revista Brasileira de Educação, Rio de Janeiro, n. 34, p. 94-103, jan./abr. 2007.

SCHÖN, Donald. The reflective practitioner: how professionals think in action. New York: Basic Books, 1983.

TARDIF, Maurice. Saberes docentes e formação profissional. Petrópolis: Vozes, 2014.

ZEICHNER, Ken. Repensando as conexões entre a formação na universidade e as experiências de campo na formação de professores em faculdades e universidades. Educação, Santa Maria, v. 35, n. 3, p. 479-504, 2010.

\section{COMO CITAR ESTE ARTIGO}

GUIMARÃES, Daniela Oliveira. Formação de professores de educação infantil e o Pibid. Cadernos de Pesquisa, São Paulo, v. 49, n. 174, p. 76-99, out./dez. 2019. https://doi.org/10.1590/198053145997 